\title{
Examining study habits in undergraduate STEM courses from a situative perspective
}

\author{
Matthew T. Hora ${ }^{1 *}$ and Amanda K. Oleson ${ }^{2}$
}

\begin{abstract}
Background: A growing body of research in cognitive psychology and education research is illuminating which study strategies are effective for optimal learning, but little descriptive research focuses on how undergraduate students in STEM courses actually study in real-world settings. Using a practice-based approach informed by situated cognition theory, we analyzed data from 61 STEM students about their study habits.

Results: Results indicate that studying is a multi-faceted process that is initiated by instructor- or self-generated cues, followed by marshaling resources and managing distractions, and then implementing study behaviors that include selecting a social setting and specific strategies. Variations in some study behaviors are also evident according to the timing of their studying (e.g., cramming), course level, discipline, and social setting. Three cases of individual student practices reveal how studying is also shaped by how the course is designed and taught, students' own beliefs about studying, and aspects of their personal lives.

Conclusions: The results indicate that studying involves various social, digital, and curricular resources, that many students persist in utilizing low-impact study strategies (e.g., re-reading text), and that the use of study strategies varies across different situations. We suggest that the focus on changing teaching behaviors that is dominant within STEM education be broadened to include a focus on instructional design that supports student self-regulatory behaviors and the adoption of high-impact study strategies.
\end{abstract}

\section{Background}

As concerns mount regarding the quality of undergraduate education, particularly in the science, technology, engineering, and mathematics (STEM) fields, policymakers, educators, and student affairs professionals are increasingly focusing on how to support student learning throughout their academic careers. Given that students' academic success is shaped by a complex matrix of psychological, cultural, and organizational factors, scholars are investigating a variety of issues that may impact student success including underlying psychological attributes such as engagement (Carini et al. 2006) and perseverance or "grit" (Duckworth et al. 2007), what instructors believe about teaching and learning (Hativa and Goodyear 2002), and the types of teaching methods used in the classroom (Freeman et al. 2014). However, while these areas of research shed light on key aspects of student

\footnotetext{
* Correspondence: hora@wisc.edu

${ }^{1}$ Department of Liberal Arts and Applied Studies, University of

Wisconsin-Madison, 21 N. Park St., Madison, WI 53715, USA

Full list of author information is available at the end of the article
}

learning, these foci overlook a key piece of the student learning puzzle-what students actually do when they leave the classroom and study.

A considerable body of literature exists on college student study skills and habits, with foci on students' cognitive styles and approaches to learning (Biggs 1987; Riding and Cheema 1991), the use of specific study techniques (Karpicke et al. 2009) and the role of study habits and time spent studying on overall student achievement (Nonis and Hudson 2010; Robbins et al 2004). Investigating the nature of study habits is important because factors related to studying such as motivation and specific study techniques have been linked to academic success. In a meta-analysis of 72, 431 students, Credé and Kuncel (2008) found that motivation and study skills (e.g., time management) were positively associated with grade point average and grades in individual courses. Furthermore, a comprehensive review of research on specific study strategies found that some (e.g., distributed practice) led to learning gains whereas others (e.g., re-reading text) did not (Dunlosky et al. 2013) and that many 
college students are not employing these study habits (Hartwig and Dunlosky 2012), and understanding why students persist in using ineffective study practices and how to change this state of affairs, from a situative perspective, is of particular importance to the field of STEM education. Thus, knowing whether or not (and why) students are using these practices is important information for instructors and student affairs/academic advising professionals.

Yet for the field of postsecondary education in general, and STEM education in particular, relatively little is known about student study habits, largely due to the lack of robust descriptive research that accounts for students' behaviors in real-world settings. The gaps in the literature are twofold. First, much of the research on studying is based on survey research or experimental studies of specific study strategies, with few qualitative, descriptive studies of how students actually study in real-world situations. Such an approach to research, that focuses on descriptive accounts of naturalistic behaviors in order to inform educational programming and reforms, is becoming increasingly important in research on reform implementation in both K-12 and postsecondary contexts (Hora 2016; Coburn and Turner 2012; Spillane et al. 2002). Second is view of study habits as decontextualized, not shaped by social, curricular, situation; given insights from situated cognition research on how activity and learning itself is "distributed, stretched over (and) not divided among" mind, tools, and social and organizational contexts (Lave 1988, p. 1), and that decision-making and behavior cannot be properly understood without close attention to the naturalistic settings in which they unfold (Klein 2008), the reliance on decontextualized survey research for insights into study habits is no longer tenable.

In this exploratory study, we utilize a practice-based approach to focus on the actual study behaviors of 61 undergraduates at three research universities in the USA and Canada who were enrolled in biology, physics, earth science, and mechanical engineering courses. Drawing upon situated cognition theory to conceptualize studying as a behavior that encompasses individual study strategies as they unfold in specific social, technological, and institutional contexts, we analyze data using inductive thematic analysis from 22 focus groups, and these students provided detailed information about their study habits that allowed us to answer the following research questions: (1) What behaviors do students taking undergraduate STEM courses engage in when studying? (2) What underlying contextual factors, if any, influence these behaviors?

We pursued this line of research because while the question "How can we teach students if we do not know how they learn?" (Coffield et al. 2004, p. 1) is important, we also wonder "How can we best support student success if we do not understand how they study?" Insights gleaned from the data presented in this paper, which indicate that studying is a complex, multi-dimensional practice that implicates cues, social resources, artifacts, and study strategies, can provide faculty and student affairs professionals with a new way to think about studying that extends the prior focus on specific, decontextualized study strategies.

Discussions regarding the state of undergraduate education in the early twenty-first century often focus on the role of the instructor and their pedagogical acumen in the classroom (e.g., Bok 2009). Indeed, much of the focus in the STEM education literature is on how to affect changes in faculty teaching practices and philosophies about student learning (PCAST 2012). While instructors certainly play an important role in facilitating student learning by crafting experiences that engage students in these ways (or not), researchers have long questioned whether enough attention has been placed on the other actor involved in the learning enterprise-the student. As Entwistle and Tait (1990, p. 170) observed, student behaviors are "part of a broader academic environment which affects learning probably as much as, if not more than, the classroom skills of the lecturer." According to this view, the student as an agent actively engaged in his or her own learning and overall experience in college is a central, if not primary, part of the teaching and learning equation that is too often overlooked.

\section{Psychological approaches to understanding study habits and academic success}

In early research on the change processes that young people undergo while in college (Pascarella and Terenzini 2005) and the factors that contribute to students' lack of persistence (Tinto 1993), higher education scholars have paid particularly close attention to the psychological factors that shape students' experiences and ultimate success (or lack thereof). For instance, attributes associated with academic success such as involvement (Astin 1984) and engagement have been used to explain students' relative success in their academic coursework (Carini et al. 2006). An underlying assumption in this literature is that students' mental stances or psychological attributes play a major role in their academic outcomes and that higher education professionals should support them by facilitating higher degrees of involvement and engagement to increase their prospects for success.

Another line of inquiry has focused on subconscious psychological traits associated with student learning including cognitive styles and approaches to learning (see Coffield et al. 2004 for a review). For example, researchers have argued that people have stable cognitive styles or "typical or habitual mode(s) of problem solving, thinking, perceiving, and remembering" that shape how they think and learn (Riding and Cheema 1991, p. 194). Another commonly used 
construct is that of approaches to studying, which refers to more elastic, changeable approaches and preferences that learners have for studying and learning (Entwistle and Tait 1990). Early work in this area argued for the existence of two distinct approaches to learning whose basic outlines persist to the present time: deep approaches to learning that involve searching for meaning and surface approaches that involve rote memorization (Marton and Säljö 1976; Biggs 1987). While such approaches to learning are theorized as being relatively stable within an individual, they can change over time with concerted effort. Furthermore, these psychological attributes should not be considered as operating independently from the context in which studying occurs (Ramsden 1979). In fact, early research in this area found that some students actively sought information in the environment (e.g., textbooks, lecture content) and then studied using what was called "cue-seeking" behavior, whereas others were more "cuedeaf" or worked to succeed without seeking hints about exams (Miller and Parlett 1974).

This focus on the origins of student's motivation to initiate studying is similar to a long-standing line of inquiry that examines the degree to which learners are able and willing to assume control of their own learning process or what is known as self-regulated learning (Zimmerman and Schunk 2001). A self-regulated learner engages in a process of initiating the learning process on their own, setting goals, identifying appropriate strategies, and reflecting on his or her own task performance-all of which ultimately leads to a decision to enact changes in future behaviors or to maintain current practices (Cassidy 2011). Self-regulated learning is a particularly valuable idea in college student success, with empirical research in this area indicating that students who exhibit high degrees of self regulation have higher rates of academic achievement as measured by persistence and grades (Boekaerts and Corno 2005).

\section{Research on study habits and skills}

Another body of literature that examines studying focuses directly on the study habits and skills that students utilize during the act of studying itself. However, what at first glance may appear to be a straightforward, easily defined term is operationalized in a variety of ways in the literature. For instance, Robbins et al. (2004, p. 276) define study skills as "activities necessary to organize and complete schoolwork tasks and to prepare for and take tests" and operationalize the construct using measures including time management, leadership skills, communication skills, and the un-defined category of "study skills and habits" (see also Credé and Kuncel 2008; Lotkowski et al. 2004). Other scholars have defined study habits in different ways, including the ability to concentrate, the scheduling of regular review sessions, and hours spend studying (Nonis and Hudson 2010). Conceptualizing study habits in terms of time spent studying is rather common, and a widely cited report by Babcock and Marks (2010) found that hours spent studying has declined from $24 \mathrm{~h}$ a week in 1961 to $14 \mathrm{~h}$ a week in 2003. In 2009, the picture was bleaker, with over half of freshmen who took the Your First College Year Survey and over half of seniors who took the College Senior Survey spending $10 \mathrm{~h}$ or less per week studying or doing homework (Ruiz et al. 2010; Franke et al. 2010).

While these studies capture important facets of studying and the role that they play in student achievement and persistence, the specific strategies and actions students actually engage in during their study sessions remain obscured. Providing more clarity on specific study habits, Karpicke et al. (2009) found that the preferred study strategy of $84 \%$ of the surveyed undergraduates was re-reading textbooks and lecture notes. Unfortunately, a study examining the utility of 10 learning techniques in the empirical literature found that habits such as these considered low utility in regard their impact on student learning, in contrast to high-utility techniques such as practice testing and distributed practice (i.e., taking tests over time), thus suggesting that many undergraduates utilize study habits that are ineffective (Dunlosky et al 2013).

Given the ubiquity of the Internet and digital media in many people's lives, researchers are also investigating how these artifacts are being used as study aids. In one study exploring student utilization of digital and "traditional" resources, researchers found that 39 and $44 \%$ of students search Wikipedia and Google, respectively, if they need help with coursework, with only $36 \%$ seeking out a faculty member (Morgan et al. 2012). Similarly, a 2010 study of 36,950 undergraduates found that 33\% used wikis, $24 \%$ used video-sharing websites, and $12 \%$ used blogging tools (Smith and Caruso 2010). Besides these more traditional digital media, including course websites hosted on institutional learning management systems, some argue that other tools that facilitate personalized learning (Dabbagh and Kitsantas 2012) and digitally mediated social learning via open Internet-based resources (Seely Brown and Adler 2008) are under-utilized in higher education. Researchers are also examining how digital media can inhibit studying, however, and Rosen et al. (2013) found middle-school, high-school, and undergraduate students were unable to remain on task for even 6 min before being tempted by Facebook or texting when studying at home.

However, the literature on study skills, strategies, and habits is limited by a tendency to reduce the complex and multi-faceted behaviors that comprise studying to metrics that cannot capture how and why students study (i.e., hours spent studying) or focus on strategies (e.g., re-reading) at the expense of other possible behaviors or choices students make. Perhaps the single largest limitation, however, is the 
lack of attention paid to the contexts within which students actually study. While some scholars have focused on the environmental contexts of studying (Kuo et al. 2004) and the interaction among study habits and social factors (Treisman 1992; Robbins et al 2004), few recent studies have attempted to describe studying behaviors as a multifaceted process that includes not only study strategies but also how situations and resources are implicated in these practices.

This is important because educational practice, whether a group of undergraduates studying for a biology course or an administrator finalizing a budget, should not be thought of solely in terms of an individual making decisions in isolation, as the context of decisionmaking as well as tools and other artifacts utilized as part of the process is critically important. In studying the practices of principals in K-12 settings, for example, researchers have utilized theoretical frameworks from situated and distributed cognition which assert that the institutional context is not a mere backdrop for activity but is instead an integral feature of individual cognition and decision-making as well as task performance itself (Halverson 2003; Hora 2012; Spillane et al 2002). In this study, we draw upon these frameworks to conceptualize studying as the discrete behaviors of individuals (e.g., reviewing notes) as they unfold within specific contexts and that implicate particular artifacts and resources.

Why does the lack of descriptive research on student study habits that adopt a situative perspective matter? Because fine-grained descriptions of people's behaviors in specific contexts and situations illuminates the specific steps people take when solving problems or performing tasks-information that can then be used by instructors and educational leaders to improve their practices and design more locally attuned interventions (Coburn and Turner 2012; Spillane et al. 2001). Educational researchers across the K-16 spectrum have argued that more practicebased research should be conducted on the various behaviors associated with teaching and learning, so that how and why educators and students make decisions in "the wild" of schools, colleges, and universities can illuminate barriers and supports to effective practice, rather than simply prescribing how people should think and act regardless of the situation (Bastedo 2012). With such a comprehensive and multi-faceted approach to describing studying, we set out to document the study habits of 61 undergraduates taking STEM courses as a corrective to the focus on both teaching and study strategies alone, in the hopes that such accounts could inform ways that educators can improve student learning and academic success.

\section{Methods}

Exploratory research is intended to examine poorly understood phenomena and generate new insights and hypotheses that can guide future research on the topic (Slavin 2002; Stebbins 2001). In this exploratory study, we examine the study habits of a group of STEM students, with a focus on describing the lived experiences and subjective interpretations of individuals and groups or what cultural anthropologists call an "emic" account of social life (Merriam 2014). The study took place at three large, public research universities in the USA and Canada that had similar undergraduate populations (approximately 25,000 students). These sites were selected due to the presence of instructional reform initiatives, which was a criterion for the larger study on STEM instructors' data driven decision-making upon which this analysis is based. The disciplines included in this study are biology, geology, physics, and mechanical engineering based on the STEMrelated focus of the larger study. For this study, a nonrandom purposive sampling procedure was used to identify faculty study participants. Faculty were included in the study population if they were listed as instructors in each institution's course listings for the 2013 spring semester. We contacted 165 instructors via email requesting their participation in the study, and 59 participated (36\% response rate). Thus, the faculty whose classes were recruited into the study were unique in that they were self-selected and taught undergraduate STEM courses at large research universities.

These instructors represented the initial pool of courses from which we selected student participants for the focus groups. We selected the focus group technique in order to collect a large amount of qualitative, indepth data in a shorter amount of time than would be possible with individual interviews (Bernard 2011). Of the 59 faculty who participated in the larger study, we asked 30 instructors they would recruit students for participation in focus groups, of which 22 instructors agreed. The 30 courses (and instructors) selected for recruitment represented the largest courses across all four of the disciplines included in the study, which increased the prospects of recruiting sufficient numbers of students. Those instructors sent email requests to their classes, and students contacted the research team if they were interested in participation. There was a $\$ 20$ incentive, and 61 students participated (see Table 1).

\section{Data collection}

A team of four researchers conducted the student focus group interviews using a semi-structured interview protocol, with each group led by one or two moderators depending upon scheduling constraints. The key question posed to participants in the focus groups was: "Please imagine for a moment how you typically study for this course - can you describe in as much detail as possible your study situation?" This question was followed by probes regarding the types of materials used for studying, 
Table 1 Sample characteristics ( $n=61,22$ courses)

\begin{tabular}{ll}
\hline Sample characteristics & Number \\
\hline Gender & 36 \\
Female & 25 \\
Male & \\
Field of study & 26 \\
Biology & 12 \\
Mechanical Engineering & 11 \\
Physics & 12 \\
Geology & \\
Level of course & 43 \\
Lower division & 18 \\
Upper division & \\
\hline
\end{tabular}

whether participants studied alone or with others, and any additional details not yet described. While the open-ended nature of the questions resulted in detailed observations about study practices, it also led to idiosyncratic accounts that were not always comparable across individuals. We also did not provide a definition for the act of "studying" during the focus groups, which was based on our goal of capturing students' own unique perceptions about what behaviors and situations constituted a study session. Each focus group included between two and six students and lasted approximately $45 \mathrm{~min}$. These focus groups were audio recorded and transcribed.

\section{Data analysis}

Transcripts were entered into NVivo qualitative analysis software and then segmented into manageable units or discrete statements by participants that encapsulated a single thought or idea (Gee 1986). First, a code list was created to segment the data that aligned with the research questions guiding the analysis. We were interested in segments related to "study strategies" and "study situations," and thus, any utterances pertaining to these two categories were sought out. Both analysts reviewed five transcripts with these two codes in mind and highlighted text fragments related to both codes and then met to ensure a common understanding of the relationship between the codes and the raw data. Upon ensuring that the codes were being applied similarly, the second author then segmented the remainder of the dataset. Second, we followed a structured approach to grounded theory that involved using a combination of a pre-existing "coding paradigm" and the inductive analysis of transcripts to develop a code list with which to analyze the entire dataset. The second author developed a preliminary code list using an inductive open-coding approach where terms or ideas mentioned by study participants themselves (e.g., rereading textbooks) were used to create code names (Glaser and Strauss 1967) while the research questions and theoretical framework were also kept in mind (Strauss and Corbin 1990). After developing the initial code list, we met to discuss the codes and revised them while reviewing text fragments and discussing the applicability of codes to the data. During this process, we attempted to derive codes that maintained as much fidelity to participants' own language and descriptions of study behaviors as possible.

The second author then developed the final code list using the constant comparative method, where each occurrence of a code was compared to each previous instance of that code in order to confirm or alter the code and/or its definition (Glaser and Strauss 1967), after which the final code list was applied to the entire dataset. At this point in the analytic process, qualitative researchers have the option of reporting recurrent themes with or without numeric counts of their prevalence. In this paper, where all study participants responded to questions in a similar fashion (e.g., specific study strategies), we elected to report the number of times a code was applied to the raw data in order to convey to readers the frequency with which a particular behavior or observation was identified in the data. In other cases where responses were more ambiguous and/or where different respondents interpreted questions differently, we report recurrent themes instead of numeric counts.

The data were also entered into a data matrix with subjects as rows and study cues, resources, and strategies as columns. These data were analyzed using exploratory data reduction methods (i.e., hierarchical cluster analysis and multi-dimensional scaling) to see if patterns across the data could be discerned. Clear patterns were not discernable, so these data were then organized to report the frequency with which particular strategies were used according to different groups of students (e.g., discipline, social situation). The results reported in this paper depict the percentage of students within each group reporting each strategy, with results weighted according to the size of each respective group.

Next, we analyzed two students and one entire focus group who provided particularly rich details about their study habits in order to depict how studying unfolds in real-world settings at the individual level. These subjects were selected because of the level of detail they provided when self-reporting their conceptions of what studying means, the contexts in which their studying occurred, and their actual study behaviors. These case studies also highlight the situated nature of studying in the influence of peers, curricular artifacts, and other features of the environment on their study habits. Finally, we examined the resulting themes to explore any patterns in the data and identified a new way of thinking about studying that is reported in this paper. 
Limitations to this study include the self-selected nature of the sample, both of the participating instructors and students, that limits generalizability of the findings to broader populations of undergraduates. Such limitations to generalizability are an inherent part of research using small, non-randomly selected samples, but their strength is in illuminating behaviors at a fine-grained level. While future research involving larger samples will be necessary to assess how widespread the behaviors reported in this paper truly are, the data do raise questions and considerations about studying that can be applied to different institutions. Another limitation is that the focus group method may introduce an element of self-censoring and social desirability bias by participants due to the public nature of the setting, which can result in incomplete or inaccurate answers to the facilitator's questions. Finally, because participants discussed their studying with varying degrees of specificity it was difficult at times to ascertain whether similar behaviors were being reported. The limitations associated with social desirability and the veracity of students' accounts could not be overcome with the current study, though future work should consider incorporating an observational component to corroborate self-reported behaviors with actual practice.

\section{Results}

Before reporting data addressing the research questions guiding the study, we first discuss how respondents had differing notions of what activities constituted "studying." For some, it meant any exposure to course material such as attending a class, whereas for others, studying implied completing assigned tasks. In yet other cases studying referred to activities that were not assigned and took place outside of class. As one student said, "I see studying more as something that I do separate from any assigned material." In addition to these task-oriented conceptions, some reported "folk" theories of the learning or ideas about phenomena that are not necessarily grounded in evidence. For example, one student stated, "Studying to me means stressing out your brain so that it realizes that the information is significant."

Thus, for the students in this study, "studying" was not easily distilled into a set of discrete strategies such as rereading the textbook or hours spent engaged in discrete strategies. Further, as we discuss below, students' views of studying also implicate a variety of strategies, social and physical settings, and resources as being involved in the studying process (Greeno 1998; Halverson 2003; Robbins et al 2004). Future research should delve more deeply into what students consider to be studying in terms of its physical, artifactual, and temporal boundaries. To maintain a consistent definition for this analysis, however, we defined studying as any interaction with course material outside of the classroom.
Cues to initiate studying and timing of study strategies Prior to engaging in particular study activities, students frequently discussed why they started studying, which centered on the core idea of "cues" that trigger study behaviors. These cues were either provided by the instructor or were internally generated. While students were not explicitly asked about what cued their study sessions, descriptions of the study processes for many students provided information for this analysis. Another important aspect of these preliminary stages of studying is when students choose to study-either throughout the semester, several days before an assessment, or the day before a test or exam (i.e., cramming).

\section{Instructor-generated cues}

Throughout a given semester, 40 students reported that instructors often provided cues regarding when and what they should study. The most important cue for students tended to be the announcement of an upcoming assessment, thus initiating the process of studying. For some, an impending assessment was the only reason for studying. Similarly, instructors' discussions about assessments (e.g., topics that would be covered) served as a primary rationale for some students to attend class. One participant said, "I go to class to (hear) the professor say this week on the exam you will see this subject or that subject." Consequently, for some students, the classroom becomes a venue in which cues pertaining to assessments are sought and then applied to their studying.

\section{Self-generated cues}

Fewer (four) participants also discussed another cue for studying, that of recognizing that they were not sufficiently prepared or familiar with the course material. One participant explained that he studied after realizing that he did not understand a concept, which then set in motion a series of study behaviors that lasted until he felt conversant with the material. He said, "....and then I realize, 'Oh man, I don't understand pulleys so well', so last week I studied pulleys until I understood them." Others reported a strong desire to learn certain skills and material so that they could reach their career goals.

\section{Timing}

Next, we discuss findings regarding when students reported engaging in study activities. For 11 respondents studying took place several days before an exam or test, while 14 reported waiting until the last day or even night before, popularly known as "cramming." While the literature indicates that cramming is an ineffective way to study (e.g., Kornell 2009), and some students recognize its limitations (e.g., one student reported that after cramming "[the information] is not still in my brain"), this mode of preparation remains a common method. Finally, 15 
respondents discussed studying throughout the term. In some cases, this practice was instigated by course-specific factors such as an instructor's use of weekly quizzes, whereas in others, the student established a regular schedule of studying on their own.

\section{Marshaling resources for studying}

After discussing cues and timing for studying, the respondents then discussed collecting and utilizing a variety of resources with which to study. In describing students' use of resources, we included references to commonly used tools such as course websites and textbooks as well as human resources that learners draw upon when studying. This represents a broader view of resources within organizations than is commonly used but captures knowledge and capabilities of instructors and staff within an educational organization (Gamoran et al. 2003). Understanding the resources used during studying is important because digital, print, and human resources and tools are used to enhance or even shape the studying act itself.

The resources discussed by the respondents included digital tools and media, print resources, and human resources, and those most commonly reported are depicted in Table 2.

\section{Digital resources}

While the most commonly reported digital tool included laptops or desktop computers, we focus here instead on the applications used by students on these now ubiquitous resources for college students. The most widely reported resource was the course website (27 students), which operated on various learning management system (LMS) platforms. These websites were developed by

Table 2 Resources participants accessed while studying $(n=61)$

Number

\begin{tabular}{ll}
\hline Digital resources & \\
Course website/LMS & 27 \\
Google & 24 \\
Wikipedia & 13 \\
Facebook/Facebook group & 9 \\
Youtube & 5 \\
Print resources & \\
Textbook & 34 \\
Lecture notes & 33 \\
Cue cards & 5 \\
Human resources & \\
Instructor & 7 \\
Teaching assistant & 7 \\
Tutoring & 3 \\
\hline
\end{tabular}

instructors who posted a variety of learning resources including videotaped lectures, readings, practice exams, and course syllabi. One student described her professor's course website as such, "So basically like any way you learn you can find it on [course website name] through all her resources and find a good way to study for you."

The next most widely used digital resource included websites for seeking out new information including Google (24) and Wikipedia (13). These websites helped students expand upon lecture notes or clarify concepts or steps in solving problems. For example, one participant noted that in lecture, he listened for key words that could be included on exams and then looked them up online, because "With the Internet and Wikipedia you just need to know a few keywords and you can learn about anything." Other resources included Facebook (9) which was used as an organizing tool and Youtube (5) for informational purposes. These results support prior research that found college students regularly utilize these online resources, even more so than their own instructors (e.g., Morgan et al. 2012).

However, the evidence suggests that technology also acts as a disruptive force in some students' study habits. Nineteen respondents reported that some digital resources, usually cell phones and Facebook, regularly disrupted their studying yet they had no strategy for managing these distractions. One student noted, "[When studying] I look up sports stuff, any excuse not to be studying....at a computer I can just click on whatever I want." To mitigate the potential distractions of the Internet or a buzzing phone, 21 students reported having developed strategies for managing distractions, often by deliberately removing them from their study "space." The optimal studying situation for one student was in an isolated cubicle in the library basement with no cell phone reception, and he would turn off his laptop's wireless Internet signal. In another case, a student went to her parent's house on the weekends for a self-imposed "no devices zone" where her phone was confiscated so she could concentrate. Thus, digital resources can both enhance and detract from an individual's studying, and students have varying degrees of success when it comes to managing the detrimental aspect of digital devices and media.

\section{Print-based resources}

Another type of resource that respondents regularly used was print-based resources such as textbooks (34) and lecture notes (33). Lecture notes took many forms including notes taken by student in class as well as notes and/or PowerPoint slides provided by the instructor, both of which were reported as important resources for studying. Another less utilized print resource discussed by five respondents was cue cards, which were mostly used to memorize key facts and formulas. 


\section{Human resources}

The last type of resource reported by students pertained to the knowledge and content-expertise of people within their courses and/or departments. These included instructors (8) as well as teaching assistants (8) and tutors (4). In some cases, the participants reported approaching instructors or teaching assistants outside of class to obtain assistance with homework, upcoming or previous exams, and challenging concepts or problems. For students who were especially struggling with the course, tutors provided expertise and one-on-one instruction that these students viewed as an especially important form of academic support.

\section{Setting and strategies}

Next, we report data that speak to the studying process itself, particularly with whom students study and the specific strategies they employ.

\section{The social setting in which studying occurs}

When describing their actual study sessions, the respondents noted whether or not they studied alone or with others. For 39 respondents, studying was often a solitary affair. Some students noted that studying alone was an explicit strategy to reduce distracting conversations with others, while others stated that it was simply a habit. In contrast, 35 students described studying in groups. In these cases, the respondents stated that group-based studying was useful because peers could provide new insights or solutions. However, because 24 students reported studying both alone and in groups, depending on the proximity to an exam or the nature of the assignment, it is clear that for some students in the sample, the social setting in which studying occurred was rather flexible and not a fixed criterion or preference.

\section{Employing specific study strategies}

The studying process next involves the selection of specific strategies or techniques. While the participants often described these strategies using imprecise or idiosyncratic terminology such that it was often not possible to align them with those discussed in the literature (e.g., Dunlosky et al. 2013), it was possible to identify several core strategies utilized by this group of undergraduate students. In this section, we elaborate on the most commonly referenced strategies (see Table 3).

Thirty-eight participants re-read or reviewed course material or notes taken in class. This strategy was discussed as both a general practice that took place throughout the term as well as an initial step in preparing for exams. For example, one participant said that he reread all of his lecture notes before working with old test materials "to try to understand what the professor had said fully" before attempting to take practice tests.
Table 3 Reported study strategies

\begin{tabular}{ll}
\hline Strategy & Number \\
\hline Reviews notes: reviews or re-reads own lecture notes & 32 \\
$\begin{array}{l}\text { Reads the textbook: reads and consults the textbook, } \\
\text { instructor provided study guides }\end{array}$ & 29 \\
$\begin{array}{l}\text { Creates study artifacts outside of class time: creates } \\
\text { cue cards, combines notes from a variety of sources, } \\
\text { takes new notes while studying, creates concept maps, } \\
\text { cheat sheets }\end{array}$ & 22 \\
$\begin{array}{l}\text { Works on problems: does problems, problem sets, } \\
\text { practice problems }\end{array}$ & 19 \\
$\begin{array}{l}\text { Works with practice tests and exams: does practice } \\
\text { exams and reads old test materials }\end{array}$ & 15 \\
$\begin{array}{l}\text { Reviews PowerPoint slides: prints instructors' PowerPoint } \\
\text { slides }\end{array}$ & 15 \\
$\begin{array}{l}\text { Works on questions: does practice questions, end-of- } \\
\text { chapter book questions, etc. }\end{array}$ & 15 \\
$\begin{array}{l}\text { Does homework: reviews old homework problems or } \\
\text { homework questions }\end{array}$ & 11 \\
$\begin{array}{l}\text { Online textbook tutorials: reviews materials on Mastering } \\
\text { Physics/Anatomy }\end{array}$ & 11 \\
$\begin{array}{l}\text { Reviews weekly quizzes: reviews and re-does old weekly } \\
\text { quizzes } \\
\text { lectures and podcasts }\end{array}$ & 9 \\
\hline
\end{tabular}

Given the broad conception of studying used in this analysis (i.e., any interaction students have with course material outside of class), we include the strategy of "doing homework" which 25 participants reported. As one participant put it: "My method of studying is pretty much to do any homework or review questions..." Homework also provided a litmus test of understanding-one participant explained how he learned a lot in class, but it really became clear when he answered the homework questions correctly.

While students reported reviewing lecture notes from class, this particular strategy involved 22 students creating their own artifacts such as cue cards, consolidating notes from different sources (some instructor-provided, others self-procured) into one set of notes, and so on. For example, one participant explained, "I write myself notes and everything is in my notes, including the textbook material and the prof's slides and what the prof said or the stuff I found in Wikipedia or everything." Others created study aids (e.g., games or cheat sheets) that were used throughout the term for study sessions.

Twenty participants reported reading the textbook in some capacity, either in full or in part, either assigned or unassigned, or they consulted the book when confronted with unfamiliar material. Often, the participants did not specify if they were re-reading, reading it for the first time, or if they were skimming. Importantly, the depth with which students read textbooks appeared to vary based on their intentions. In one case, a student 
explained, "Sometimes I just go through the chapter we're going to go through in class and I just read all the captions for the images (to prepare for the lecture) so I know what we're going to talk about and then afterwards I'll read through the chapter." In most cases, however, students spoke more ambiguously about reading.

Nineteen participants reported working with test materials provided by the instructor or students who had previously taken the course. One participant reported her routine as taking practice exams in a simulated test-taking environment, followed by an item-byitem analysis of her performance. Another talked about reviewing tests from previous years and randomly selecting problems to complete for practice. In both cases, the materials provided the students with an opportunity to monitor their level of understanding (or lack thereof) while also becoming attuned to the testmaker's approach.

Working on problems was a strategy reported by 17 participants. Although ambiguous, the specific nature of the term "problems" likely refers to mathematical or computational problems given that many of these participants were enrolled in science or engineering courses. As one participant said, "I just find every single practice problem that I can get my hands on and do it."

Eleven participants reported working on a variety of questions while studying. In one class, students worked on study questions or short essay prompts that review that day's lecture. Further, instead of relying on practice exams, one student in that class reported, "I've found the best way to do well on the test is not to do all of her practice exams, but do (the) study questions." Others reported working on end-of-chapter questions and completing discussion questions as an effective study strategy.

Taking quizzes related to course material outside of class was another method of studying reported by 11 participants. Sometimes the instructor provided the quiz to test comprehension after a reading assignment. One student who takes bi-weekly extra-credit quizzes provided by her instructor said, "I take them pretty seriously, I'll prep a little bit before them even though they're only five questions and if I get something wrong I'll read (about it)."

\section{Other factors influencing the study process}

In addition to specific cues, resources, and study strategies, respondents also discussed various situations or factors that influenced their study behaviors.

\section{Role of instructor in providing resources for studying}

Student's use of resources during their studying depends, in part, on the instructor and his/her provision of particular resources within the course. For example, some instructors provided their students with a variety of modalities and tools for learning (e.g., podcasts, supplementary readings, online lecture notes) that other students might not have had access to in other courses or with other instructors. These can be offered as inclass resources, or more commonly, embedded within the course's website or LMS. Students can then select from the resources made available by their instructors, as well as resources that they find on their own, to construct their own unique study situation.

Course characteristics and discipline The participants described how disciplinary content and course structure also influenced the strategies and resources they used. Some students perceived that different disciplines required different approaches to studying. One participant said, "You can't study math how you would study biology, right?" The student followed up this observation by describing how studying for a math course entailed doing numerous problem sets, while a biology course required extensive reading, memorization, and understanding laboratory assignments. Other course characteristics that influenced teaching were the assessments and teaching methods used in the course. For instance, one student explained how her approach to preparing for multiple-choice exams emphasized a surface knowledge of selected topics: "Instead of looking at a topic and being able to discuss it for paragraphs at a time in like an essay format, I'll try to memorize details that I feel are important." Another respondent student noted that his studying "tends to match the style of the class" so that in a class taught with PowerPoint slides, his studying entails "a lot of time looking at slides," whereas a more interactive class involves focusing on concepts and hands-on activities. This student's approach to studying suggests that an instructor's teaching style may have consequences for student learning not only through in-class comprehension of material but also by sending messages to students regarding the best way to study.

Personal situations and dispositions The participants also alluded to personal factors that influenced their studying such as the lack of time due to heavy course loads and/or work schedules, family situations, and health-related issues. Additionally, the participants brought to a course pre-existing dispositions and experiences that influenced their approach to studying. One of these pertains to historic study habits from high school, where some students attempted to alter their "old" study behaviors to fit with the "new" expectations and demands of the university, while others simply continued using what had worked for them previously. Finally, student's personal reasons for taking a course (e.g., to satisfy degree requirement, curiosity) also shaped how participants approached their studying. 


\section{Patterns in cues, resources, and strategies}

Next, we sought to explore whether or not patterns in the data existed in regard to how cues, resources, and strategies were inter-related or not. Preliminary analyses using exploratory data techniques did not reveal discernable patterns, and no clear links were evident across the three primary components of studying identified in the data (i.e., cues, resource use, strategies). Instead, we chose to examine patterns in the use of study strategies considered effective in the literature (e.g., Dunlosky et al. 2013) according to two aspects of study behaviors (i.e., study timing, social setting) and two variables related to subject characteristics (i.e., course level and discipline). All analyses include weighted averages.

First, when looking at when studying occurs according to three groups of students (i.e., less than 1 week prior, cramming, throughout term), some data points stand out (see Fig. 1). Crammers review notes more often than others (94\%), while those studying less than 1 week prior to exams use more textbooks (73\%), study questions (55\%), and video (36\%) than other groups and those studying throughout the term or semester use problem sets (53\%) more often than others. These data indicate that some variation in study strategies is evident depending on when students choose to study.

Second, when organizing the data according to two groups (i.e., studying alone or studying in groups) differences in study strategies are also evident (see Fig. 2). Note that some students reporting doing both, hence, the large numbers in both groups that do not sum to 60 (42 and 36, respectively). Students studying alone tend to review notes (64\%) and textbooks (52\%) and also do practice tests $(24 \%)$ and quizzes $(19 \%)$ more than those studying in groups. In contrast, those studying in groups create study artifacts (47\%), do problems (31\%) and questions (31\%), and use online materials such as video (14\%) and the Mastering Physics/Anatomy videos (19\%).

Third, when the data are organized according to the discipline of the course students were enrolled in at the time of data collection, additional points of variation are evident (see Fig. 3). Again, students may or may not be majors in these fields but discussed their study habits in relation to these disciplines. Students taking biology courses (26) report reviewing notes (69\%) and textbooks (46\%), doing practice tests (31\%) and questions (35\%), and reviewing videos $(27 \%)$ more than students taking courses in other fields. Students in physics courses (11) reported creating artifacts (64\%), doing problem sets (82\%), and mastering resources $(45 \%)$ more than others. Mechanical engineers and geology students did not report any study strategies more than other groups.

Finally, the data indicate that study habits vary by course level, with students in upper division courses (18) reporting using certain study strategies more than those in lower division courses (43), including practice tests (33\%), questions (39\%), video (28\%), and mastering physics or anatomy resources (33\%). The students in lower division courses reported reviewing notes (58\%), creating artifacts (37\%), reviewing textbooks (51\%), and doing problems (42\%) and quizzes (16\%) more than the students in upper division courses (see Fig. 4).

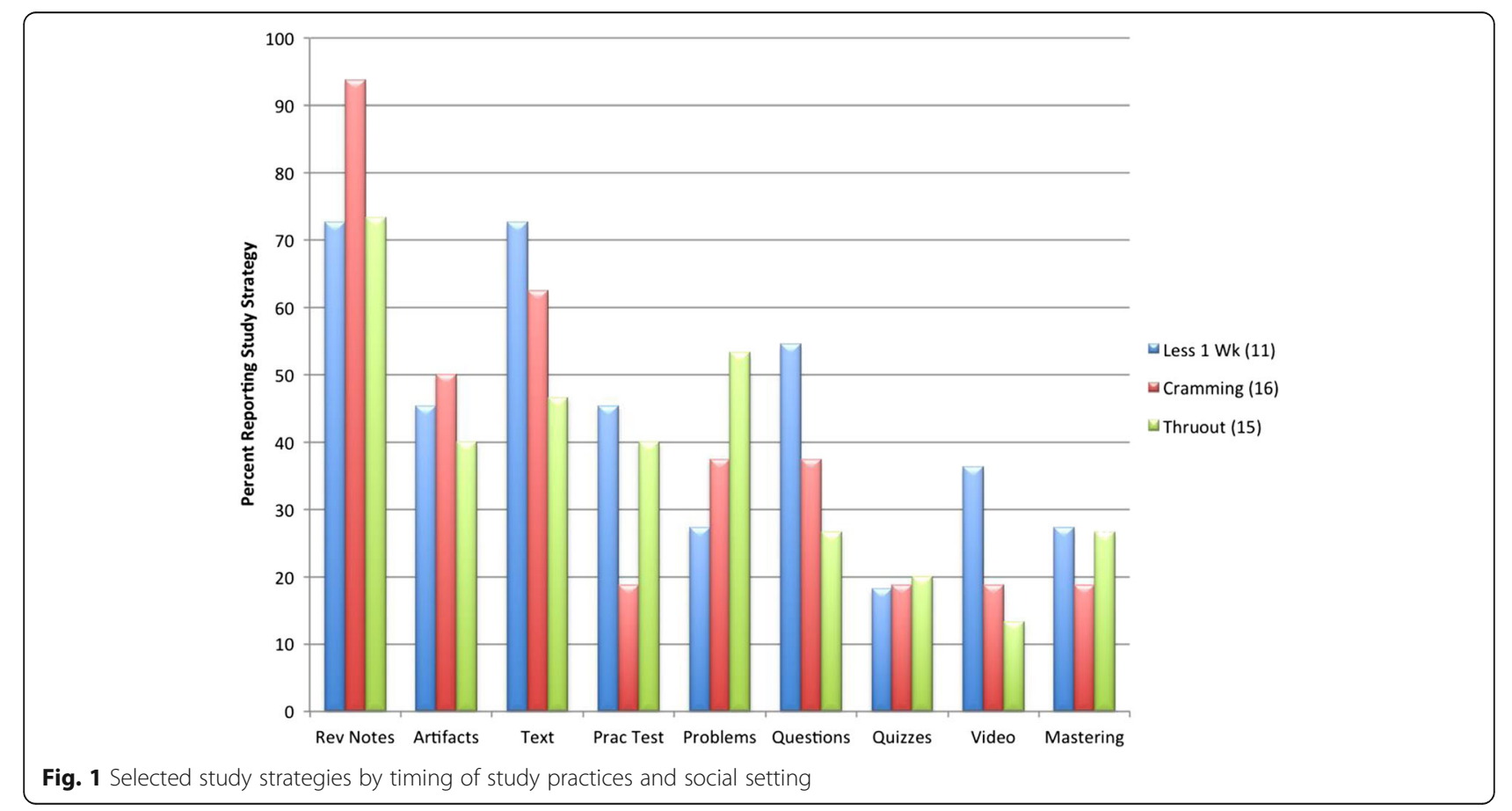




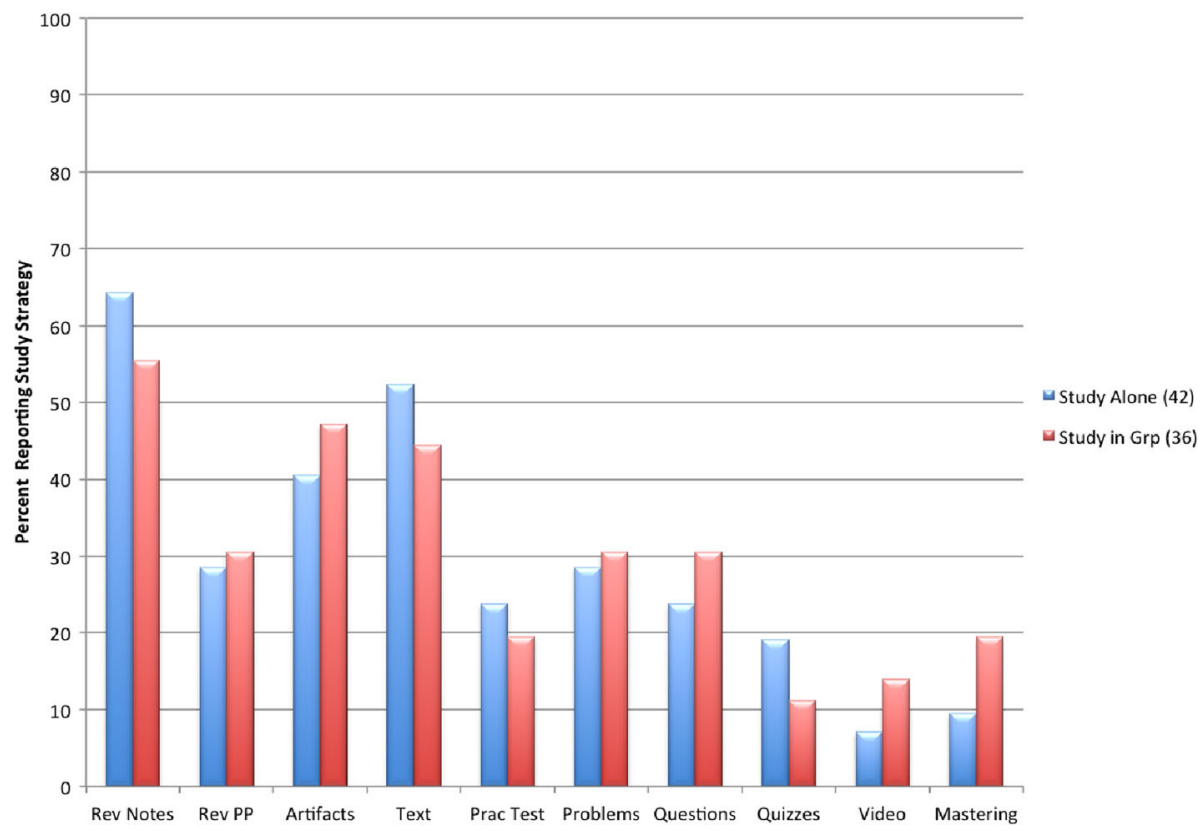

Fig. 2 Selected study strategies by timing of study practices and social setting

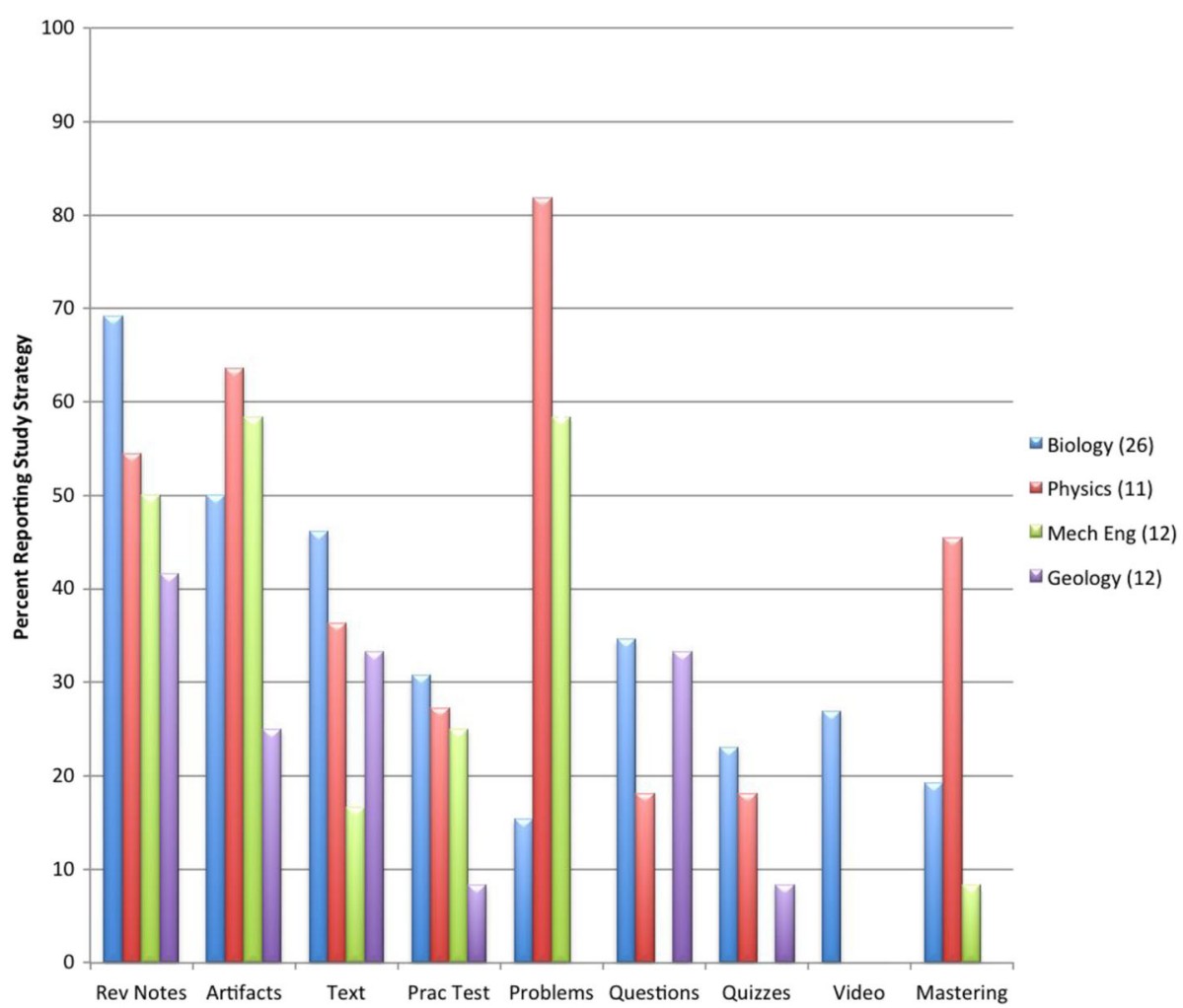

Fig. 3 Selected study strategies by discipline and course level 


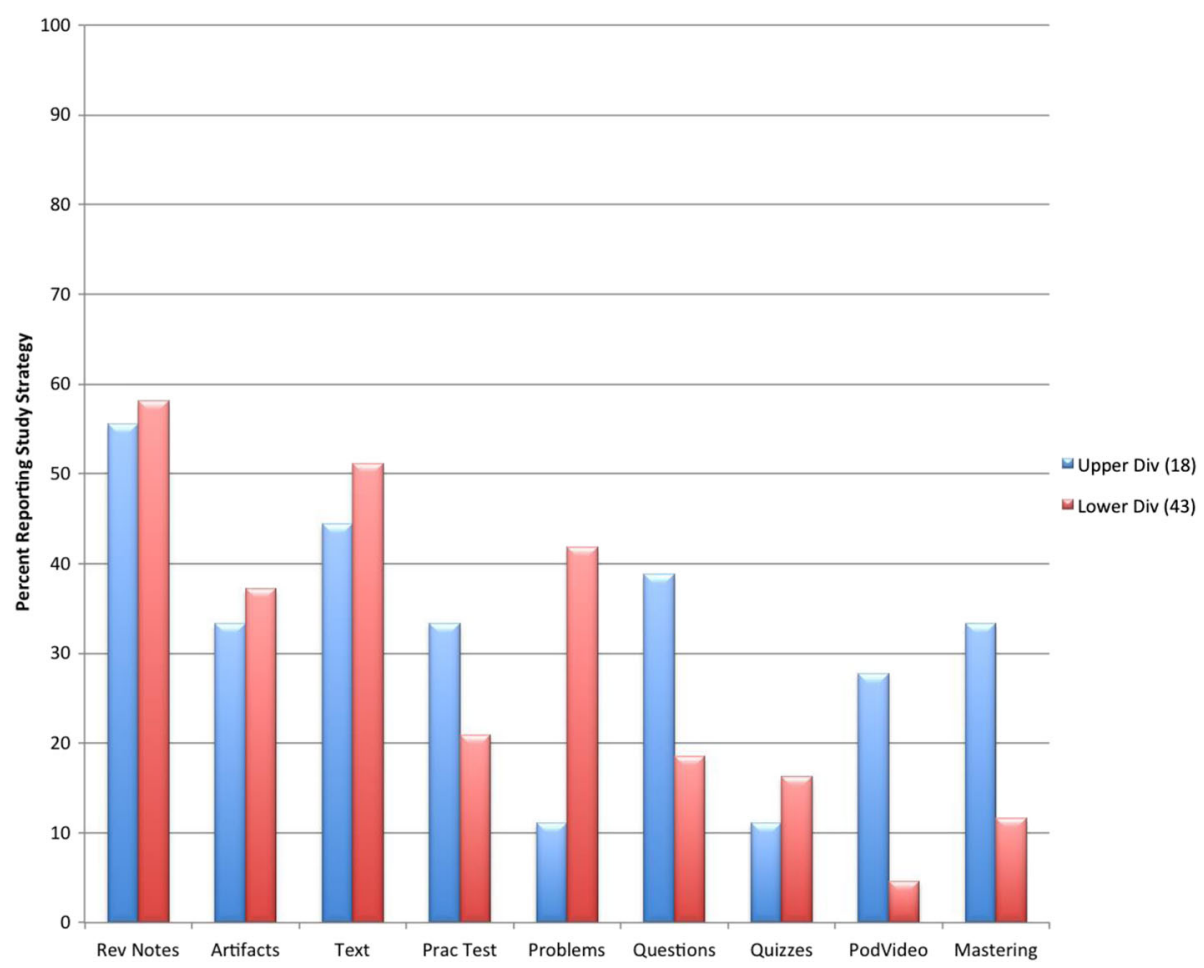

Fig. 4 Selected study strategies by discipline and course level

\section{Case examples}

Finally, to illustrate how each of these sets of findings is evident in students' own real-world experiences, we present three in-depth analyses of students' actual studying practices. The first two cases are those of individual students-Larry and Brianna-whose study behaviors reflect different sequences of decisions that link particular cues, resource use, and strategies. The final case is that of a group of five students in a single course (i.e., upper division anatomy and physiology). These cases illustrate how studying is a complex, idiosyncratic practice, while also being shaped by the social, institutional, and technological milieu in which students operate.

Larry. When we spoke with Larry he was studying for an upper level biology course that was required for his major. He first talked about his personal view of what studying means, stating that:

Studying to me means stressing out your brain so that it realizes that the information is significant. Basically, your brain can be lazy when it doesn't think that something's important and stressing it is what makes it retain information. So studying for exams is a lot about stressing your brain out.

This theory of how the brain and learning work thus set the stage for Larry's subsequent study habits, which was a process that began in the classroom. There, he "frantically" wrote on the instructor's PowerPoint slides that he printed off before class, labeling images, drawing arrows, and identifying mechanisms for cell signaling that were being discussed in class. Larry said that he did not necessarily understand the concepts at the time but took the notes down to reference later. In fact, it is not until he finds the time to sit in the library and read the relevant sections of the textbook that "it all comes together and finally makes sense." While reading, he writes down key terms and their definitions in a notebook. For Larry, the library represented an important resource in his education because he does not own the book because he cannot afford it. Thus, he spent a lot of time in the library reading one of two copies on reserve. He also attended the optional recitation section for the course where he was able to speak with the instructor one-onone and earn extra credit.

While he tried to study throughout the term, with his demanding course load and work schedule, he often only had time to study 3 or 4 days prior to an exam. Describing his study habits as "messy" and comprised of "lots of big stages," Larry first gathered his notes from classroom sessions and his review of the textbook and then made flashcards for key concepts from the course. He also completed the end-of-chapter quizzes in the text and reviewed (and retakes) any old quizzes or exams from the course. The day before the exam, he tells himself "Wow Larry, 
you really have to get to it now," and he sequestered himself at the library to review his notes and difficult concepts in the textbook and to re-watch videotaped lectures from the course website. All along, he deliberately studied alone because he had to maximize the limited time available for studying, such that he "cannot afford to sit around and have people talk about other stuff." After several hours in the library reviewing these materials, Larry generally felt ready for the exam. Altogether, in Larry's case, studying is an act that is instigated by instructor's cues (i.e., upcoming exam), informed by a folk theory of the mind, involves a variety of curricular resources, and is strongly influenced by his personal situation.

Brianna. Next, we consider the case of Brianna who was enrolled in a lower division physics course when we met with her group. Her general approach to studying was to hope that the instructor was direct about expectations and guidelines because then, "the ball is in (her) court and (she) either learns the material or not." Thus, Brianna was relatively self-motivated but relied on instructors to provide cues regarding when and how hard to study. This motivation is also sparked by her aspiration to attend medical school, which requires doing well on the Medical College Admission Test (MCAT). Brianna observed that "even if I get an A on a test but have no idea what is going on, it wouldn't set me up to be in a good place for studying the MCAT in the future."

In addition, she relied heavily on what she called her own preferred "learning style," which centered on reading and re-reading text, whether it be the textbook or notes taken in class. Given her reliance on text and notes, Brianna observed that, "I pretty much show up to lecture just to write down what he's saying." The notes she took in class then became an important artifact for later studying, as she used them to create flashcards from her notes (and the textbook) and an outline for the course that is added to throughout the term. During her actual study sessions, Brianna either studied alone, reviewing her notes, scanning various digital resources, and doing practice problems, or with a group of friends in the library where she typically had on her headphones while surrounded by classmates who intermittently helped one another out on difficult problems.

Brianna's use of digital technology is notable because she described online videos, the course website, the Internet, and social media as the "majority" of the resources she used to study. For example, she consulted free online tutoring videos (especially videos featuring one tutor in particular at the University of California at Berkeley), which helped her fill out her notes and summaries from the class and textbook. Overall she described the Internet as a "great resource" for finding course materials (e.g., slides, notes, exams, and videos) from other instructors teaching the same course at other colleges or universities. The questions these other instructors ask their students provides insights into what Brianna perceives her professor may ask, so she values their outsider's perspective. Further, when doing her homework problems, she looked up the solutions online, even when she was confident about her answer. She does this to ensure that she is "approaching [the problem] in the right way" or to see if there are alternative methods to solving the problem. This, in turn, gives her a more "holistic grasp of the question." Finally, in this and other courses, social media sites such as Facebook provided a place where she and her friends posted questions and shared approaches to different problems. Notably, most of the digital resources Brianna utilized were not part of the official course materials organized by her instructor and posted on the course website.

Thus, for Brianna studying involves a process of rereading course materials and tools such as cue cards and digital media, largely in response to instructor's cues about upcoming exams or homework. Driven by the desire to attend medical school introduced an element of motivation that made her take studying rather seriously.

Dr. Wells' course. The final case is that of five female students taking an upper division anatomy and physiology course with Dr. Wells. In this course, which had an enrollment of 525 students across three sections, Dr. Wells had provided a rich array of learning resources on the course website that included weekly postings of videotaped lectures and PowerPoint slides, weekly practice questions, old exams, and links to other online resources. The students in the focus group noted that Dr. Wells did not simply post these resources and let students figure out how to utilize them but instead discussed in class how to use each tool and study with them. As Angelica noted, "She just does a really great job of giving us a lot of different ways to study." Jacquie concurred, saying that while an online course she was taking was similarly well-resourced, "Dr. Wells provides more alternative methods to study which is what makes her course stand out." Ultimately, in providing such a variety of resources for studying, Dr. Wells had crafted a learning experience that stood out for these students. For Bailey, who had little experience with the material, this was particularly important because "it's really hard to stick your fingers in and get going," and if you only have a textbook to work with, the entry points to the material are limited, often inaccessible and not particularly engaging.

In many ways, Dr. Wells was running a partially flipped classroom, in that students watched videotaped lectures online and came to a class that was highly interactive and engaging. During the class, Dr. Wells was constantly in motion, using her iPad to project slides on the screen 
while also writing and drawing using a stylus pen. Many questions were asked of students, including peer-based activities and small group discussions. Linda noted that Dr. Wells also emphasized important ideas across various formats such as clicker questions, practice tests, and study questions, such that "the repetition is awesome...even if you're tired or distracted, eventually you'll still get it."

In terms of how these students actually studied in the course, weekly study questions (i.e., short essay questions that recap entire lectures) provided by Dr. Wells played an important role. For Jacquie, who said that she essentially crams before the exam-saying "well yeah, that's why we study, for the exams"-her lecture notes, study questions, the mastering anatomy online resources, and old test materials were all utilized during study sessions. After discussing the course with her friends, however, she concluded that the best way to succeed in the course was "not to do all of her practice exams but to do those freaking (weekly) study questions." Angelica said that "I noticed when I don't do the study questions I don't do very well." This approach is similar to the technique of distributed practice, or regularly spaced testing of material over time, which is one of the high-impact study strategies identified by Dunlosky and colleagues (2013). Robin also spent $3-4 \mathrm{~h}$ after each class doing the study questions, along with a variety of other tools including the mastering anatomy activities, notes, lecture videotapes, and old test materials. In fact, while the group varied on the timing of their studying, all were cued by the instructor, used a variety of digital and print resources and between four and six study strategies. This reliance on multiple resources and study strategies is unsurprising given how Dr. Wells structured her course and guided her students in regard to studying. Within this learning environment, students then developed their own approach to studying but in ways strongly shaped by the resources and strategies Dr. Wells had embedded in the course structure.

\section{Discussion}

The field of higher education in general and STEM education in particular continues to grapple with how to best facilitate learning, persistence, and retention throughout students' postsecondary careers. Does the answer lie in changing teacher behaviors alone, such as the adoption of active learning techniques, structural responses such as reducing student debt and dealing with the rising price of college, or is success also dependent upon student attributes such as engagement and motivation? What these questions reveal is that students' experiences in college are shaped by a variety of influences and that the intersection among policy, economics, organizations, and instruction provides a more accurate frame for thinking about student success than a search for a single "magic bullet" solution.
The same idea applies to thinking about the role that effective study strategies play in student learning. While the use of high-impact practices such as distributed practice is certainly a key ingredient in leading to student learning (Dunlosky et al. 2013), it is important to recognize that students' adoption of these practices requires several antecedent conditions to be in place before this can happen. These include knowledge of these methods, time to study, access to the resources required to study in this manner, and so on. Similarly, studying is not simply about using strategies such as re-reading text or doing practice problems but is a process that involves cues about when to study, the timing of their actual study sessions, which resources to utilize, where to study, and which strategies to employ. How these stages unfold in practice are also shaped by a variety of factors such as a students' personal life, the course material, and how instructors structure courses and make learning resources available. This is not to diminish the importance of high-impact study strategies but instead to point out that there are many steps taken by students to get to the point where they can sit down and utilize them with some regularity.

In the remainder of this paper, we discuss how this exploratory study contributes to the literature on college student study habits, particularly through the articulation of a multi-dimensional conception of studying that can provide instructors and administrators with a more nuanced account of how students engage in studying. In combination with the data reported in this paper as well as developments in educational technology and research, such an account also highlights the importance of instructional design that facilitates students' use of highimpact strategies, diversified learning tools, and selfregulatory capabilities.

\section{A new approach for thinking about undergraduates' study behaviors}

The results reported in this paper confirm and extend prior research on college student study habits. The data reinforce prior research that some of the most dominant study strategies utilized by students include reviewing notes and re-reading textbooks (Karpicke et al. 2009), utilize a variety of digital resources (Smith and Caruso 2010), and also rely on instructors to provide cues to begin studying (Miller and Parlett 1974). While the study described here is limited by a small sample size and lack of data on the impact of various study habits on learning outcomes, it was designed to shed light on fine-grained behaviors among a small group of students in order to advance our understanding of decision-making and action in specific social, organizational, technological contexts. In doing so, we extend the prior literature by offering an integrative multi-stage approach for thinking about study behaviors. 
When interpreting the results from this exploratory study, we observed that students discussed their studying in terms of stages that began with cues to study and ended with their use of specific strategies. Along the way, they made decisions about who to study with and which resources to use, an account consistent with a situative theory of cognition, which posits that mental activity and social action is situated within specific socio-cultural and organizational contexts while also being distributed among mind, tool, and activity (Greeno 1998; Spillane et al. 2001). In other words, studying is not solely a matter of a "mind" sequestered with a book and highlighter pen, or a behavior that could be distilled into hours spent studying or the prevalence of a particular strategy, but instead involves people interacting with one another and various tools in specific situations (Seely Brown and Adler 2008). This is not to diminish the value of experimental work that does hone in on specific aspects of studying such as how students self-pace their study or time spent on specific tasks (Bjork, Dunlosky and Kornell 2013) but instead is an argument that a broader perspective of the act of studying itself is also useful.

Consequently, based on the data presented in this paper, we suggest that a new way of thinking about studying is warranted that includes the following components: (1) recognizing the situation and detecting cues to initiate studying, (2) marshaling resources and managing distractions (or not), (3) selecting a time and social setting to study, and then selecting specific strategies, and (4) engaging in a period of self-reflection. We illustrate this approach using the three cases reported earlier in the paper (see Fig. 1).

Some caveats are necessary when interpreting this figure. First, while the stages of cue detection and timing, resource use, and strategies are based on data from this paper, the self-regulative period is not. Instead, it is included as a post-assessment phase of reflection and commitment that the literature indicates is an important aspect of learning (Zimmerman and Schunk 2001). Second, we do not claim that all 61 participants in the study progressed through each of these steps, but instead that this conception of studying captures the broad range of behaviors and experiences students reported engaging in during a recent study session. As a result, we are not suggesting that this account of studying is generalizable to all students but is a heuristic device for thinking about studying in a more multi-dimensional manner than is common at the present time.

Thus, we argue that conceptions of the act of "studying" extend beyond a focus on discrete, decontextualized factors such as hours spent studying or the use of specific strategies (e.g., re-reading text). In making this argument, we highlight the importance of ecological validity when thinking about study habits in general and interpreting laboratory-based research in particular. In other words, understanding how findings from the literature about "effective" study habits may vary according to disciplinary, social, institutional, or personal situations will be important for future work in the area. We also suggest that a more multi-dimensional conception of studying can also be a useful interpretive framework for educators, instructional designers, and administrators to begin thinking more broadly and strategically about how their courses are designed (or not) to foster effective study habits. By recognizing that studying involves multiple states, resources, strategies and actors, it becomes necessary to move beyond simply providing "how-to" guides for studying or recommendations for students to use high-impact practices to instead think about the role that cue-seeking, resource acquisition, and distraction management play in shaping students' study habits. With a more situative view of studying in mind, it is possible to consider how the course as a whole creates an environment that prompts particular study behaviors, such as Dr. Wells' provision of various learning tools via her LMS that prompted students to study with them. Thinking of studying in these terms, in the remainder of this paper we highlight ways that educators can facilitate or support effective studying and learning practices: fostering selfregulated learning and using principles from instructional design to encourage high-impact studying.

\section{Fostering self-regulated learners}

One of the most pressing issues facing educators is the fact that many students continue to utilize ineffective study practices, such as re-reading textbooks or cramming the night before an exam. Informing some lowimpact practices are "faulty mental models" (p. 417) about how memory and learning work, such as the view that information can be recalled and played back like a recording (Bjork, Dunlosky and Kornell 2013). Instead, the retrieval process involves reconstructing knowledge from various stored memories, is heavily dependent on specific cues, and that upon cueing information in memory becomes reinforced. Essentially, students need to understand that in order to create a library of information in their minds that is easily accessed and retained over the long term requires a "meaningful encoding of that information" which involves integrating information into a network of connected ideas and then regularly practicing retrieval of that information (Dunlosky et al. 2013).

Besides becoming more sophisticated learners and theorists about how the mind works, it is clear that students can also benefit from more guidance about how to more effectively study and learn. Educational psychologists argue that becoming a more adept learner is not simply about amassing tips and strategies 
about how to study but is based on becoming what is known as a self-regulated learner, which is the "self-directive process by which learners transform their mental abilities into academic skills" (Zimmerman 2002, p. 65). Selfregulation is not just a quality or personal aptitude, however, but is best thought of as a sequence of states that include forethought (i.e., plans for studying), performance, and self-reflection. Motivation to initiate studying on one's own is important, but perhaps more critical is the selfmonitoring of performance, especially the ability to scrutinize and interpret failure and make corrections (Boekaerts and Corno 2005). Furthermore, while considerable barriers exist for students to develop selfregulative habits, such as a belief that intelligence is "fixed" and not malleable (Yeager and Dweck 2012) and assumptions that learning should be simple and unproblematic (Bjork, Dunlosky and Kornell, 2013), helping students to develop this aptitude is critical because it is a core aspect of success not only in school but also in life and the workplace (Pellegrino and Hilton 2012).

So how, if at all, can STEM educators embed selfregulatory skills into their courses? Setting aside for the moment the extent to which self-control, goal setting, and responsibility should be learned in the home, grade school, or various other cultural fields during childhood, the fact remains that it is possible to teach some aspect of self-regulatory competencies in the college classroom (Nilson 2013). One strategy is to create a classroom environment with high expectations and a low- to zerotolerance policy for irresponsible behavior or late assignments, thereby encouraging if not forcing students to set goals for themselves and achieve them. Another strategy is the widely used instructional wrapper, which refers to prompts for students to reflect on their performance before and after an assignment or activity, which trains students to regularly reflect on their study habits and approach to learning (Lovett 2013). Other ideas include modeling learning strategies such as self-monitoring and summarizing in front of students in what is known as a "cognitive apprenticeship" (Palincsar and Brown 1984), using small group work tasks designed to spark selfregulation (Fitch et al. 2012) and assigning open-ended tasks and assessments requiring students to choose strategies and take control of their learning (Boekaerts and Corno 2005).

We conclude this discussion about self-regulation with a note about digital media. While online resources and digital devices can play an important and productive role in facilitating student learning (Dabbagh and Kitsantas 2012; Smith and Caruso 2010), it is evident from the data that they can detract from focused study. Thus, another aspect about self-regulation is the willingness and ability to remove digital distractions when they are not serving a productive purpose, such as the students in this study who deliberately went to libraries without wireless Internet or parents' homes where devices were confiscated. As will be discussed in the next section, technology can and should be part of educators' instructional toolkit, but students would be well served by adopting more self-regulated stances when it comes to the presence of technology in their study sessions.

\section{Encouraging personalized learning and high-impact studying through course structure}

Next, we turn to issue of how instructors, through the deliberate design of their courses, can facilitate effective study habits. Here, we focus on two aspects of effective studying: the use of multiple representations and modalities and the use of high-impact strategies. In both cases, we can look to the example of Dr. Wells' course where she embedded within the structure of the course itself opportunities for students to draw upon various learning tools while also imposing a high-impact study habit (i.e., distributed practice) via weekly practice questions.

First, providing students with a variety of learning resources and tools offers them a variety of entry points with which to explore the material. The rationale for doing so is not to support students' distinct learning styles, an idea that is popular but unsupported by the empirical evidence (Pashler et al. 2008), but instead is based on the fact that learners that engage with varied representations of an idea or concept demonstrate improved learning outcomes (Pellegrino and Hilton 2012). In addition, the provision of various learning tools is useful because today's learners are broadly proficient in developing personalized learning pathways, whether for academic or personal purposes, using online resources and social media (Dabbagh and Kitsantas 2012). In doing so, many create social learning environments, or what some call "participatory cultures," where people develop online learning communities where they collectively create, share, and learn from each other (Jenkins et al. 2006). Essentially, the idea is to make available a repertoire of learning tools and media for students that they can then select from to approach the material from multiple perspective and according to their own unique way of engaging with different learning modalities.

The second approach for facilitating effective study habits pertains to the structure of a course, from the timing and nature of assessments to the types of learning activities students are required to do. Again, consider the example of Dr. Wells, who embedded within her course an assessment strategy that forced her students to engage in the highimpact study habit of distributed practice. Through weekly practice questions, students were required to regularly take mini-exams on different topics (Dunlosky et al. 2013). Spacing out study sessions on distinct topics enhances 
learning through the spacing effect and also by introducing comparisons or "interference" across topics, which results in higher-order representations or complex mental models that not only are repositories of information but also facilitate transfer and retention (Bjork, Dunlosky, and Kornell 2013).

Similarly, the role of course structure in facilitating student learning has been well documented in STEM education, where pre-class reading quizzes and weekly practice exams have been linked to improved student learning (Freeman et al. 2011), and even in reducing the achievement gap between white and under-represented minority students, because highly structured courses with regular practice may introduce study and learning skills to students with little experience from high school (Haak et al. 2011). The takeaway here is that as educators, we can design our courses and teach our classes with explicit attention towards creating (and mandating) situations for students to engage in certain study habits.

\section{Conclusions}

The attention currently being placed on STEM instructors and their pedagogical acumen as key facilitators of student learning is well-placed, but the relationship between teaching and learning is anything but direct, linear, and unproblematic. What students decide to do in terms of when and how to study act as critical intermediaries between what instructors do in the classroom and students' ultimate performance in college. As Entwistle and Tait suggested over 25 years ago, (1990, p. 170), students' behaviors and strategies "affects learning probably as much as, if not more than, the classroom skills of the lecturer." On this point, there are both promising and troubling signs. While students are increasingly utilizing varied resources and media in a deliberate and creative manner to advance their studies, some study methods that are demonstrably ineffective continue to be widely used. The exploratory study reported in this paper offers a new, multi-dimensional way to think about studying that suggests future research directions exploring undergraduate study habits including similar descriptive research with larger samples and additional disciplines, experimental research focusing on specific strategies under different conditions (e.g., resource use, cues for studying), and examining the relationship between course structure and studying.

Ultimately, students must take responsibility for their learning and strategize ways to create situations-whether in a quiet library basement or a group study session online-where they can effectively study and learn. However, postsecondary educators must also be cognizant of the pressures facing today's college students and the fact that many have not been taught how to engage in high-impact study habits but instead rely on re-reading highlighted text.
One of the guiding principles for instructional design should be the idea that it is no longer tenable to assume that students have been taught how to effectively study and learn prior to their matriculation into a college or university. While students bring a wealth of new learning habits and technological acumen to the twenty-first century classroom - whether online or face-to-face-they still need guidance in how to study. This conclusion, however, should not lead to complaints about unprepared students or a failed K-12 sector but instead needs to spark postsecondary educators to carefully design of rich and engaging learning environments that sparks self-regulatory habits of mind and encourages high-impact studying, so that students are well positioned to succeed.

\section{Acknowledgements}

The authors would also like to thank Jana Bouwma-Gearhart and Jennifer Collins for their involvement in this study and collecting data reported in this paper.

\section{Funding}

This research was supported by a grant from the National Science Foundation (DUE\#1224624) for the Tracking the Processes of Data Driven Decision-Making Study (http://tpdm.wceruw.org).

\section{Authors' contributions}

AO participated in the design of the study and data collection, led the data analysis, and collaborated with $\mathrm{MH}$ to draft the manuscript. $\mathrm{MH}$ conceived of the study, led the design, participated in data collection and analysis, and finalized the manuscript. Both authors read and approved the final manuscript.

\section{Competing interests}

The authors declare that they have no competing interests.

\section{Author details}

${ }^{1}$ Department of Liberal Arts and Applied Studies, University of Wisconsin-Madison, 21 N. Park St., Madison, WI 53715, USA. ${ }^{2}$ Wisconsin Center for Education Research, University of Wisconsin-Madison, Madison, USA.

Received: 1 August 2016 Accepted: 6 January 2017

Published online: 01 February 2017

\section{References}

Astin, A. W. (1984). Student involvement: a developmental theory for higher education. Journal of College Student Development, 40(5), 518-529.

Babcock, P., \& Marks, M. (2010). Leisure college, USA: the decline in student study time. American Enterprise Institute for Public Policy Research, 7, 1-7.

Bastedo, M. N. (2012). Organizing higher education: a manifesto. In M. N. Bastedo (Ed.), The organization of higher education: managing colleges for a new era (pp. 3-17). Baltimore: The Johns Hopkins University Press.

Bernard, H. R. (2011). Research methods in anthropology: qualitative and quantitative approaches (5th ed.). Lanham: Altamira Press.

Biggs, J. (1987). Student approaches to learning. Hawthorn: Australian Council for Educational Research.

Bjork, R. A., Dunlosky, J., \& Kornell, N. (2013). Self-regulated learning: Beliefs, techniques, and illusions. Annual review of psychology, 64, 417-444.

Boekaerts, M., \& Corno, L. (2005). Self-regulation in the classroom: a perspective on assessment and intervention. Applied Psychology, 54(2), 199-231.

Bok, D. (2009). Our underachieving colleges: a candid look at how much students learn and why they should be learning more. Princeton: Princeton University Press.

Carini, R. M., Kuh, G. D., \& Klein, S. P. (2006). Student engagement and student learning: testing the linkages. Research in Higher Education, 47(1), 1-32.

Cassidy, S. (2011). Self-regulated learning in higher education: identifying key component processes. Studies in Higher Education, 36(8), 989-1000. 
Coburn, C. E., \& Turner, E. O. (2012). The practice of data use: an introduction. American Journal of Education, 118(2), 99-111.

Coffield, F., Moseley, D., Hall, E., \& Ecclestone, K. (2004). Learning styles and pedagogy in post-16 learning: a systematic and critical review. London: Learning Skills Network.

Credé, M., \& Kuncel, N. R. (2008). Study habits, skills, and attitudes: the third pillar supporting collegiate academic performance. Perspectives on Psychological Science, 3(6), 425-453.

Dabbagh, N., \& Kitsantas, A. (2012). Personal learning environments, social media, and self-regulated learning: a natural formula for connecting formal and informal learning. The Internet and higher education, 15(1), 3-8.

Duckworth, A. L., Peterson, C., Matthews, M. D., \& Kelly, D. R. (2007). Grit: perseverance and passion for long-term goals. Journal of Personality and Social Psychology, 92(6), 1087-1101.

Dunlosky, J., Rawson, K. A., Marsh, E. J., Nathan, M. J., \& Willingham, D. T. (2013). Improving students' learning with effective learning techniques: promising directions from cognitive and educational psychology. Psychological Science in the Public Interest, 14(1), 4-58.

Entwistle, N. J., \& Tait, H. (1990). Approaches to learning, evaluations of teaching, and preferences for contrasting academic environments. Higher Education, 19(2), 169-194.

Fitch, T., Marshall, J., \& McCarthy, W. (2012). The effect of solution-focused groups on self-regulated learning. Journal of College Student Development, 53(4), 586-595.

Franke, R., Ruiz, S., Sharkness, J., DeAngelo, L., \& Pryor, J. (2010). Findings from the 2009 administration of the College Senior Survey (CSS): National aggregates. Chicago: Higher Education Research Institute at the University of California Los Angeles.

Freeman, S., Haak, D., \& Wenderoth, M. P. (2011). Increased course structure improves performance in introductory biology. CBE-Life Sciences Education, 10(2), 175-186.

Freeman, S., Eddy, S. L., McDonough, M., Smith, M. K., Okoroafor, N., Jordt, H., \& Wenderoth, M. P. (2014). Active learning increases student performance in science, engineering, and mathematics. Proceedings of the National Academy of Sciences, 111(23), 8410-8415.

Gamoran, A., Anderson, C. W., Quiroz, P. A., Secada, W. G., Williams, T., \& Ashman, S. (2003). Transforming teaching in math and science: how schools and districts can support change. New York: Teachers College Press.

Gee, J. P. (1986). Units in the production of narrative discourse. Discourse Processes, 9, 391-422.

Glaser, B. G., \& Strauss, A. L. (1967). The discovery of grounded theory: strategies for qualitative research. New Brunswick: Aldine Transaction.

Greeno, J. G. (1998). The situativity of knowing, learning, and research. American psychologist, 53(1), 5-26.

Haak, D. C., HilleRisLambers, J., Pitre, E., \& Freeman, S. (2011). Increased structure and active learning reduce the achievement gap in introductory biology. Science, 332(6034), 1213-1216.

Halverson, R. (2003). Systems of practice: how leaders use artifacts to create professional community in schools. Educational Policy Analysis Archives, 11(37), 1-35.

Hartwig, M. K., \& Dunlosky, J. (2012). Study strategies of college students: are selftesting and scheduling related to achievement? Psychonomic Bulletin \& Review, 19(1), 126-134.

Hativa, N., \& Goodyear, P. (Eds.). (2002). Teacher thinking, beliefs, and knowledge in higher education. Norwell: Kluwer Academic Publishers.

Hora, M. T. (2012). Organizational factors and instructional decision-making: A cognitive perspective. The Review of Higher Education, 35(2), 207-235.

Hora, M. T. (2016). Navigating the problem space of academic work: How workload and curricular affordances shape STEM faculty decisions about teaching and learning. AERA Open, 2(1), 1-19.

Jenkins, H., Clinton, K., Purushotma, R., Robison, A. J., and Weigel, M. (2006). Confronting the challenges of participatory culture: media education for the $21^{15 t}$ century. Chicago: The John D. and Catherine T. MacArthur Foundation.

Karpicke, J. D., Butler, A. C., \& Roediger, H. L., II. (2009). Metacognitive strategies in student learning: do students practice retrieval when they study on their own? Memory, 17(4), 471-479.

Klein, G. (2008). Naturalistic decision making. Human Factors, 50(3), 456-460,

Kornell, N. (2009). Optimising learning using flashcards: spacing is more effective than cramming. Applied Cognitive Psychology, 23, 1297-1317.

Kuo, J., Hagie, C., \& Miller, M. T. (2004). Encouraging college student success: the instructional challenges, response strategies, and study skills of contemporary undergraduates. Journal of Instructional Psychology, 31(1), 60-67.
Lave, J. (1988). Cognition in practice: mind, mathematics and culture in everyday life. Cambridge: Cambridge University Press.

Lotkowski, V. A., Robbins, S. B., \& Noeth, R. J. (2004). The role of academic and non-academic factors in improving college retention. ACT Policy Report, Retrieved from http://ww.cfder.org/uploads/3/0/4/9/3049955/the_role_of_ academic_and_non_academic_factors_in_improving_college_retention.pdf.

Lovett, M.C. (2013). Make exams worth more than the grade: using exam wrappers to promote metacognition (pp. 18-52), in Using reflection and metacognition to improve student learning: across the disciplines, across the academy, ed. Kaplan, M, Silver, N., LaVague-Manty, D., \& Meizlish, D. Sterling, VA: Stylus Publishing.

Marton, F., \& Säljö, R. (1976). On qualitative differences in learning: I. Outcome and process. British Journal of Educational Psychology, 46, 4-11.

Merriam, S. B. (2014). Qualitative research: a guide to design and implementation. San Francisco: John Wiley \& Sons.

Miller, C. M., \& Parlett, M. R. (1974). Up to the mark: a study of the examination game. London: SRHE.

Morgan, G., Moskal, P., Wolf, A., Dziuban, C., McMartin, F., \& Morrill, J. (2012). Understanding student use of digital learning resources. [Powerpoint slides]. Retrieved from http://bit.ly/1viZRsY

Nilson, L. (2013). Creating self-regulated learners: strategies to strengthen students self-awareness and learning skills. Sterling: Stylus Publishing.

Nonis, S. A., \& Hudson, G. I. (2010). Performance of college students: impact of study time and study habits. The Journal of Education for Business, 85, 229-238.

Palincsar, A. S., \& Brown, A. L. (1984). Reciprocal teaching of comprehensionfostering and comprehension-monitoring activities. Cognition and Instruction, $1,117-175$.

Pascarella, E., \& Terenzini, P. (2005). How college affects students: a third decade of research. San Francisco: Jossey-Bass.

Pashler, H., McDaniel, M., Rohrer, D., \& Bjork, R. (2008). Learning styles concepts and evidence. Psychological science in the public interest, 9(3), 105-119.

Pellegrino, J. W., \& Hilton, M. L. (Eds.). (2012). Education for life and work: developing transferable knowledge and skills in the $21^{15 t}$ century. Washington, DC: National Academies Press.

President's Council of Advisors on Science and Technology (2012). Report to the President. Engage to excel: Producing one million additional college graduates with degrees in science, technology, engineering and mathematics. Washington, D.C.: Executive Office of the President.

Ramsden, P. (1979). Student learning and perceptions of the academic environment. Higher Education, 8(4), 411-427.

Riding, R., \& Cheema, I. (1991). Cognitive styles—an overview and integration. Educational Psychology, 11(3-4), 193-215.

Robbins, S. B., Lauver, K., Le, H., Davis, D., Langley, R., \& Carlstrom, A. (2004). Do psychosocial and study skill factors predict college outcomes? A metaanalysis. Psychological Bulletin, 130(2), 261-288.

Rosen, L. D., Carrier, L. M., \& Cheever, N. A. (2013). Facebook and texting made me do it: media-induced task-switching while studying. Computers in Human Behavior, 29, 948-958

Ruiz, S., Sharkness, J., Kelly, K., DeAngelo, L., \& Pryor, J. (2010). Findings from the 2009 administration of the Your First College Year (YFCY): national aggregates. Los Angeles: Higher Education Research Institute at the University of California Los Angeles.

Seely Brown, J., \& Adler, R. P. (2008). Open education, the long tail, and learning 2.0. Educause Review, 43(1), 16-20.

Slavin, R. E. (2002). Evidence-based education policies: transforming educational practice and research. Educational researcher, 31(7), 15-21.

Smith, S. D., \& Caruso, J. B. (2010). Key findings: the ECAR study of undergraduate students and information technology. Boulder: EDUCAUSE Center for Applied Research.

Spillane, J. P., Halverson, R., \& Diamond, J. B. (2001). Investigating school leadership practice: a distributed perspective. Educational Researcher, 30(3), 23-28.

Spillane, J. P., Reiser, B. J., \& Reimer, T. (2002). Policy implementation and cognition: reframing and refocusing implementation research. Review of Educational Research, 72(3), 387-431.

Stebbins, R. A. (2001). Exploratory research in the social sciences. Qualitative research methods in the social sciences, 48. Thousand Oaks: Sage Publications.

Strauss, A., \& Corbin, J. M. (1990). Basics of qualitative research: grounded theory procedures and techniques. Thousand Oaks: Sage Publications, Inc.

Tinto, V. (1993). Leaving college: Rethinking the causes and cures of student attrition. (2nd ed.). Chicago: University of Chicago Press. 
Treisman, U. (1992). Studying students studying calculus: a look at the lives of minority mathematics students in college. The College Mathematics Journal, 23(5), 362-372.

Yeager, D. S., \& Dweck, C. S. (2012). Mindsets that promote resilience: when students believe that personal characteristics can be developed. Educational Psychologist, 47(4), 302-314.

Zimmerman, B. J. (2002). Becoming a self-regulated learner: an overview. Theory into Practice, 41(2), 64-70

Zimmerman, B. J., \& Schunk, D. H. (Eds.). (2001). Self-regulated learning and academic achievement: theoretical perspectives. Hillsdale: Lawrence Erlbaum Associates.

\section{Submit your manuscript to a SpringerOpen ${ }^{\circ}$ journal and benefit from:}

- Convenient online submission

- Rigorous peer review

- Immediate publication on acceptance

- Open access: articles freely available online

- High visibility within the field

- Retaining the copyright to your article

Submit your next manuscript at $>$ springeropen.com 